\title{
SOCIAL AND POLITICAL CRITICISMS EMBEDDED IN CHINESE MYTHS AND LEGENDS
}

\author{
HE Xiyao \\ School of English Studies \\ Zhejiang International Studies University \\ Hangzhou, China \\ e-mail: hexiyao@zisu.edu.cn
}

\begin{abstract}
Chinese myths and legends, as popular cultural products, may be subjected to the analytical methods of cultural studies, which is the approach this study adopts when investigating their complex relationship with Chinese society and history. In particular, the social and political criticisms embedded in these myths and legends are studied, and this is done through exploring the reasons for the prominence of the embedded criticisms in Chinese myths and legends, and sorting out the general trend of their development. The prominence is accounted for by the harsh censorship and the influence of the Chu spirit and Taoism on Chinese culture. ${ }^{1}$ In the development of these criticisms, four stages are marked, each (cor)responding to the historical circumstances and with its own distinct feature. The study concludes with the historicity of Chinese myths and legends; the criticisms are embedded in them and they, in turn, are embedded in Chinese society and history.
\end{abstract}

Keywords: censorship of culture, Chinese myths and legends, Chu spirit, cultural studies, social and political criticisms, strategies and tactics, Taoism

\section{APPROACH ADOPTED IN THIS STUDY}

Among the various approaches to the study of Chinese mythology - and of mythology in general - an important one that has persisted throughout the last century and has remained influential to this day is to study the complex relationship between mythology and society, i.e., how the two have affected, structured, and shaped each other. Malinowski is generally regarded as a pioneer of this approach, who asserted the "sociological charter" of myth - i.e., myth's function in supplying any given society with "a retrospective pattern of moral values, sociological order, and magical belief" (1948: 120-22). In the second half of the twentieth century, Malinowski's approach was furthered (and 
at the same time challenged) by the structuralists, who laid more emphasis on the persistent patterns and underlying structures which get repeated in myths from different times and places, as Lévi-Strauss has put it: "repetition has as its function to make the structure of the myth apparent" (1955: 443). The structuralist approach was skillfully applied to the study of Chinese mythology by Sarah Allan. In The Heir and the Sage: Dynastic Legend in Early China (1981) she studied the binary opposition between the hereditary and the moral principle in political successions, as revealed in early Chinese myths. Besides Allan, other scholars have also studied the relationship between Chinese mythology and Chinese society from a number of non-structuralist approaches in recent decades. For example, disagreeing with Allan's structuralist approach, Anne Birrell sticks to Malinowski's "sociological charter" in her analyses of several Chinese myths in order to reveal "a more powerful layer of mythic significance" (1993: 7); Mark Edward Lewis examines how, during the transformational period from the Warring States (the second half of the Eastern Zhou dynasty) to the early empire, tales of the sage kings constituted a "mythology of statecraft" in legitimizing state violence and establishing new order (Lewis 2009: 557); and Robin McNeal diverges from the others in exploring myths' relationship with not the traditional, but the modern, Chinese society, using monuments of mythical figures on the new Chinese landscape for case studies (McNeal 2012: 679).

Despite the different approaches and conclusions of these scholars, they nevertheless share one thing in common, namely, that in their studies they all focus on the constructive and formative functions of myths in society -i.e., how myths help to establish, enforce, and maintain order and authority. Such a focus has its merits and yields, but at the same time it could also lead to the neglect of the other side of the coin, that is to say, the deconstructive and subversive functions of myths - how myths also have the potential to mock, challenge, or even disrupt established order and authority.

This other side, however, has been duly noted by some Chinese scholars, most notably Yuan Ke and Tian Zhaoyuan. Yuan is generally regarded as the most distinguished and influential Chinese scholar in this field in the second half of the twentieth century. In his magnum opus, A History of Chinese Mythology, he forcibly argues that one distinctive characteristic of mythology is "a revolutionary attitude toward reality" (Yuan 1988b: 18), and in another work, Chinese Myths and Legends (1988a), he keeps highlighting this revolutionary attitude as he anthologizes Chinese myths and legends from different historical periods. Tian disagrees with Yuan about the revolutionary attitude, seeing it as an unnecessary yardstick in measuring myths. Instead, his focus is placed on the "conflicts" between myths in history, which reflect the conflicts between different social groups at large - for example, between different ethnic groups, between 
different ruling cliques, and between the ruling and the ruled (Tian 1998: 61-68). And it is within these conflicts that the deconstructive and subversive functions of myths are usually revealed. For example, Tian offers a brilliant analysis of how the royal power was derided and challenged through the blasphemy of royal myths by the folk (1998: 405-414).

The major reason why the deconstructive and subversive functions of myths, largely overlooked by many scholars in the West, were duly noted by Chinese scholars, such as Yuan Ke and Tian Zhaoyuan, was perhaps due to the influence of Marxist theories on the latter, most of whom have worked, or been educated, from the 1950s to the 1970s, when Marxism was the absolutely dominant ideology in education and researches. At the time, theories such as "class struggle as the drive for the progress of human society" were inculcated and applied in almost all philosophical argumentations, literary and artistic criticisms, and social and historical analyses. Even after the 1970s, Marxist ideology still left a trace in their research orientations and academic outlook, as can be detected in the terminology of their writings. With the emphases of Marxist theories on "revolution" and "conflict", it would not be difficult for them to notice the deconstructive and subversive side of myths.

What has been said above should not be taken as a negative evaluation of these Chinese scholars' efforts and achievements. On the contrary, my argument is that Marxist theories, when applied properly, can help us see things that might otherwise be overlooked. In recent decades, the discipline that has benefitted most from Marxist theories is perhaps cultural studies: many scholars of cultural studies are leftists influenced by Marx, and many theories in cultural studies actually derive from Marxist theories. In general, cultural studies pays special attention to the social and political tension embedded in cultural artifacts, production and phenomena, and views these as a field of power struggle, a field where different classes, genders, races, etc., vie with each other for expression, legitimacy, and even dominance, as Bourdieu has put it: "[t]he literary or artistic field is a field of forces, but is also a field of struggles tending to transform or conserve this field of forces" (1993: 30; italics in the original). And what is interesting to note is that when investigating the different forces in this field of struggles, cultural studies oftentimes takes sides not with the dominating, but with the dominated; not with the powerful, but with the powerless; not with the advantaged, but with the disadvantaged. In other words, it concerns itself primarily with the deconstructive and subversive in culture.

Chinese myths and legends, as products of culture, may also be subjected to the analytical methods of cultural studies, and that is the approach I have adopted in this study. In particular, this study focuses on the social and political criticisms embedded in these myths and legends. Such criticisms were some- 
times directly expressed, and sometimes only vaguely implied. But whatever the form of the criticisms, they certainly embodied a "structure of feeling" (Williams 1965 [1961]: 80) of those who created, transmitted, and revised these myths and legends. And it is the purpose of this study to uncover such a "structure of feeling". Besides, efforts are also made to sort out the different forms the criticisms took at different historical stages, in order to infer the general trend of their development and explore the mechanism of their interaction with the development of Chinese history.

\section{SCOPE OF THIS STUDY}

This article covers Chinese myths and legends from remote antiquity all the way down to the Qing dynasty. This is undoubtedly a very broad scope, and such a broad scope means that the study is only a general survey rather than a detailed and in-depth investigation of the individual myths and legends. As has been said before, the purpose is to infer a general trend, and further researches dealing with more details may be carried out along this line.

In terms of the object of the study, I have included both myths and legends rather than only the former because there is still much controversy with regard to the extension of 'myth' - i.e., what can and cannot be regarded as myth - which may vary tremendously from one scholar to another. For example, whereas Lévi-Strauss and E. B. Tylor see myths as restricted to 'primitive' societies, for Eliade and Cassirer even the moderns have myths of their own (Segal 2004: 29-55). A similar controversy has occurred in China. Early Chinese scholars tended to see myths as emerging only from the very ancient past; for example, in the 1920s Mao Dun defined myths as "stories widely told by the folk in remote antiquity" (2011 [1928]: 96). But in the 1980s Yuan Ke proposed his well-known theory of "myth in the broad sense", and incorporated into the category of myth not only stories from remote antiquity, but also legends, folklores, Buddhist and Taoist tales, mythic novels, etc., of the later ages (Yuan 1988b: 1-13). As can be expected, Yuan's theory was sharply criticized after its publication by the scholars who stuck to "myth in the narrow sense", some of whom went as far as saying that his theory had "led to many unnecessary deviations in the study of [Chinese] mythology since the 1980s" (Wu 2009: 9). But, interestingly, there were also scholars, such as Tian Zhaoyuan, who thought that Yuan's definition of myth was "still a bit too narrow" (Tian 1998: 60), and tried to broaden it even further. The scholar who went the farthest in that direction is perhaps Ye Shuxian, who regarded traditional Chinese culture as essentially mythologically encoded. According to Ye, myth is what permeated almost every aspect of 
traditional Chinese culture - customs, rituals, architectures, etc. - and ironically that is why it remained invisible to most Chinese people: "the traditional Chinese people never used the word 'mythology', because they had always been living in it - it dominated in all their ideas and behavior" (Ye 2010: 012).

Faced with such controversies, it would be safer for me to use 'myths and legends' rather than only the former, because the object of this study is not limited to the primitive society, but also ranges over the following dynasties. 'Myths' and 'legends' may be distinguished in terms of their origins if one adopts a narrow understanding of myth, but even if that is the case, it can still not be denied that the two share some important common features, two in particular: firstly, both contain, almost invariably, a 'fantastic' element, usually with some divine, supernatural or magical powers involved; secondly, both have been, or still are, popular among certain groups of people, with a wide and enduring circulation. Taken together, these features render myths and legends worthy research objects of cultural studies, because encoded in these fantastic tales is the structure of feeling of those who created, transmitted, and revised them.

\section{REASONS FOR EMBEDDED CRITICISMS}

As has been shown above, myths and legends, like other cultural products, are necessarily a field of power struggle. It follows that there would be social and political criticisms in myths and legends everywhere in the world. However, in the Chinese case, that critical element is unusually prominent, outshining its counterparts in most other cases. The prominence itself requires an explanation. Why were Chinese myths and legends so charged with criticisms? And what were the social, cultural, and political factors that led the Chinese to vent so much of their dissatisfaction and anger in these fantasy tales?

The above-mentioned prominence may be accounted for in two ways. On the one hand, in comparison with other societies, the traditional Chinese society was characterized by its harsh censorship of culture, which in general intensified one dynasty after another, culminating in the large-scale literary inquisition (文字狱) during the Ming and Qing dynasties. Censorship meant that the masses could not express their dissatisfaction and anger directly, but had to resort to some indirect devices, dressing up their criticisms in seemingly harmless cultural products and expressing their dissatisfaction and anger through implications and innuendoes. The device of indirect criticism was on record as early as in The Book of Songs, the first collection of poems in Chinese literature, dating from the eleventh to the seventh century BC. In this collection there is one 'air (风)' - i.e., a song circulating among the masses, called "Big Rat", in which 
the exploiters and extorters are symbolically referred to as a big, greedy, and loathsome rat. The first stanza of the poem runs as follows:

BIG rat, big rat,

Do not gobble our millet!

Three years we have slaved for you,

Yet you take no notice of us.

At last we are going to leave you

And go to that happy land;

Happy land, happy land,

Where we shall have our place.

(The Book of Songs 2005 [1937]: 309)

Instead of directly accusing and denouncing the exploiters and extorters, the song adopts a symbolic image to vividly capture their repulsive features and express the singer's disgust with them. This tactic is partly due to the limitation of freedom of speech, but at the same time it also enhances the critical effect of the poem - indirect insinuations, when exerted with skill and cunning, can be more effective than direct statements.

Although this song contains few fantastic elements, it is essentially adopting the same indirect device and embodying the same critical spirit as the myths and legends did. However, the song is not without a 'weakness'; namely, it is not indirect enough - it is actually not difficult to see through the symbol it adopts and the message it tries to convey furtively. Harsher censorship in the later dynasties meant that criticisms in this form were no longer acceptable. As a result, the criticizers had to resort to even more subtle and furtive means. To use Michel de Certeau's paradigm, the rulers adopted more and more powerful strategies in their ideological control, to escape the discipline of which the masses had to come up with even more ingenious tactics. The tension and interaction between the strategies and tactics largely resulted in the metamorphoses of the criticisms throughout Chinese history, as we shall see later.

If censorship also existed, in varying degrees, in other cultures and societies, then the other reason is more unique to China; namely, the influence of the Chu spirit and Taoism on Chinese culture. Chu was located in the southern part of China, and starting from antiquity it was culturally distinguished from the Central Plain (中原) area in the north, which later became the center of dynastic and imperial power. This cultural distinction was most saliently reflected in mythology, and was noted early on by some Chinese scholars. For example, in 1928 Hu Shi (1999 [1928]) observed keenly that in The Book of Songs, a literary output almost exclusively of the north, there was "no trace of mythology", while in the south, there were "abundant myths", as can be seen in the works such as 
The Songs of Chu. As for the reason for such a contrast, Hu attributed it simply to the "unimaginativeness" of the northerners and the "imaginativeness" of the southerners (1999 [1928]: 47-48). Another scholar, Mao Dun, agreed with Hu about the contrast itself but had a different view on its causes. According to Mao, the northerners were no less imaginative than the southerners and had created myths of their own, but most of these myths had fallen into oblivion during the Warring States period, and one important reason for that is the "historicization of mythology" (Mao 2011 [1928]: 4) - i.e., the gods and mythical heroes were humanized into historical figures, and the irrational elements in the myths were either rationalized or eliminated. During the historicization process, Confucius and his later followers played a pivotal role. Confucius was a practical and secularly-oriented man - among the four things he did not wish to discuss was "the supernatural" (Confucius 2003: 70) - and attached great importance to human relationships, seeing it as deserving more attention than ghosts and spirits. When one of his disciples asked him for a definition of wisdom, he answered, "[w]orking to ensure social harmony among the common people, respecting the ghosts and spirits while keeping them at a distance - this might be called wisdom" (Confucius 2003: 23; emphasis added). Because of his practical mind and secular orientation, Confucius deleted many 'irrational and ridiculous' passages when editing previous historical and literary works: "The Book of Songs was edited by Confucius, and Confucius did not wish to discuss ghosts and spirits" (Mao 2011 [1928]: 4). Besides, he also rationalized many mythical records through cunning interpretations (Yang \& An 2005: 33-34). A later historian, Sima Qian, who contributed considerably to the historicization process by humanizing the mythical figures, admired Confucius greatly and was largely following his steps. Thus, through the efforts of Confucius and his followers, a large bulk of myths were banished into oblivion and lost forever.

Fortunately, Confucius was from the north, and during its initial stage, the influence of his school was limited to the northern part of China. In the south another culture prevailed, namely, the Chu culture, out of which emerged another influential school - Taoism. Of the two progenitors of Taoism, Laozi was a native of $\mathrm{Chu}$, and Zhuangzi, whose philosophical outlook was strongly influenced by the Chu culture, was of Chu descent. Taken together, the spirit of the Chu culture and Taoism formed a vital antithesis of and counterbalanced Confucianism in shaping Chinese culture in a number of ways.

Firstly, as a northerner living in the Eastern Zhou Dynasty, Confucius inherited and tried to revive the Zhou culture which had thrived in the north but was on its decline at the time: "The Zhou gazes down upon the two dynasties that preceded it. How brilliant in culture it is! I follow the Zhou" (Confucius 2003: 23). However, the kingdom of Chu was culturally distinct from Zhou; as 
Feng Youlan notes, the Chu people were of non-Chinese origin, who only rose to prominence later (Feng 1952: 175-176). Consequently, in contrast to Confucius's admiring attitude, the Chu culture had always remained independent from and untamed by the Zhou culture. The kingdom of Chu was unwilling to submit to the authority of the Zhou emperor - King Zhuang of Chu once made an inquiry to a messenger from Zhou about the size and weight of the Nine Tripod Cauldrons (九鼎) in the Zhou palace, a provocative gesture that showed his intention to seize them and replace the Zhou emperor as the supreme ruler. This unruly and rebellious spirit was carried on by the later generations. At the end of the Qin dynasty, one leader of the rebellion, Xiang Yu, was from $\mathrm{Chu}$, and called himself “Overlord of Western Chu (西楚霸王)”. Even today, in the dialect of Hubei province, where the kingdom of Chu was largely located, there is still the expression “not surrendering to Zhou (不服周)", meaning "not willing to admit defeat'.

Secondly, in contrast to Confucianism's 'into the world (入世)' attitude and active participation in state politics, the Chu culture contained an 'out of the world (出世)' element, i.e., staying away from state politics and leading a reclusive life. Of all the recluses that Confucius met during his travels, many were from Chu (Feng 1952: 175). The most famous of them is perhaps Jieyu, the madman of Chu (楚狂). According to the Analects, Jieyu once passed by Confucius, singing him a song that ended with a warning that "[t]hose who participate in government these days court nothing but danger"; Confucius descended from his carriage wanting to walk to him, but he scurried away so that in the end Confucius did not get the chance (Confucius 2003: 215). By remaining detached from state politics, recluses such as Jieyu could adopt a non-cooperative and critical attitude toward the authorities. Later on this reclusive practice persisted throughout the dynasties and became an important element in Chinese culture.

Thirdly, unlike Confucianism's practical and secular orientation, the Chu culture abounded in witchcraft and supernatural beliefs, which produced and preserved plenty of myths and legends. It is precisely such a milieu that gave rise to the first great romantic poet in China, Qu Yuan, who wrote his despise of the political sycophants and sympathy for the masses into his imaginative verses. The most important contributor to The Songs of Chu, Qu Yuan, filled his lines with names and tales of the deities, through whom he launched a series of social and political criticisms. Thanks largely to $\mathrm{Qu}$ Yuan, The Songs of Chu became a major repertoire of Chinese mythology (Yang \& An 2005: 33-34).

However, the Chu culture and Taoism, which had prospered during the Eastern Zhou Dynasty, gradually abated since the unification by Emperor Qin Shi Huang; they were further relegated to a marginal position after Emperor Wu of Han's policy of abandoning all other philosophies and promoting only 
Confucianism (罢黜百家, 独尊儒术). One result of the relegation is that humanitarian rationalism, advocated by Confucianism, became the dominant spirit in Chinese culture, as Ge Zhaoguang (1987: 22) pointed out:

The unification of Qin and Han dynasties and the flourishing of Confucianism led to the gradual abating of the spirit of the Chu culture visà-vis humanitarian rationalism; the cultural tradition of humanitarian rationalism gradually replaced the romantic literary tradition as was represented by The Songs of Chu.

Nevertheless, despite the relegation and marginalization, the Chu spirit and Taoism were never completely banished from Chinese culture. They persisted, though in a metamorphosed form, in the Taoist religion, which began to flourish toward the end of the Eastern Han Dynasty. And the flourishing of Taoist religion became "one of the media for the revival of Chu spirit in literature" (Ge 1987: 22). Taoist religion, which had its origin in Taoism, preserved several elements from the Chu culture: on the one hand, many Taoist adherents led a reclusive life, stayed detached from state politics, and were more or less critical of the authorities; on the other hand, the Taoist religion was rich in imagination, with all its deities, esoteric practices, and elaborate rituals, which gave rise to abundant myths and legends. The combination of the mythical and the critical was manifest in the works of many romantic writers associated with the Taoist religion, most notably Li Bai. Li was a Taoist convert, and his poems contained many mythical figures and tales from Taoist religion, which were oftentimes employed to launch social and political criticisms. For example, at the beginning of the poem "Song of Mount Lu - To Censor Lu Xuzhou" he wrote, "I am just like from the Chu country a man queer, / Singing phoenix songs at Confucius with a sneer" (Tang Poems 2011 [2004]: 63), which shows a strong identification with the Chu spirit (through reference to Jieyu) and rivalry with Confucianism. In another poem, "Ascending Mount Tianmu in a Dream - A Song of Farewell”, after describing the carefree Taoist deities encountered in his dream vision, he lamented at the end of the poem when he woke up from the dream: "How can I lower brows and stoop before men in power / And have to keep my face and heart all the time sour!" (Tang Poems 2011 [2004]: 66). Here the non-cooperative and critical attitude toward the authorities is obvious; moreover, it derives from the poet's witnessing the carefreeness of the Taoist deities in his dream. Thus it can be seen that the Taoist religion preserved and fused the mythical and the critical spirit of Chu culture and Taoism, using one as the conveyor of the other. And since Taoist religion contributed greatly to Chinese myths and legends, it also brought the critical spirit in Chu culture and Taoism into the latter. 
The two reasons stated above - censorship on the one hand, and the spirit of the Chu culture and Taoism on the other - resulted in the prominence of the critical element in Chinese myths and legends. However, the external manifestations of that internal element did not stay the same throughout the dynasties, but were constantly adapting to the changing historical circumstances and went through a series of transformations, which are discussed in the next section.

\section{TRANSFORMATIONS OF THE EMBEDDED CRITICISMS}

This section examines the transformations of the embedded criticisms and the different stages they went through. In doing so, one has to organize the myths and legends into chronological order and map them onto Chinese history. This, however, is a daunting task because it is extremely difficult and in many cases impossible to date the origins of the myths and legends, especially the early ones. Most of them had been circulated and transmitted for centuries before they were recorded in written form. What is worse, the transmitters and recorders may have tampered with and distorted them according to social, political or personal needs; they may even have conjured up stories of their own and passed these off as centuries-old myths and legends. Such a possibility has been noted early on by Chinese scholar Gu Xiegang, who is generally regarded as the initiator of the systematic study of Chinese mythology. In his examination of the ancient records, $\mathrm{Gu}$ discovered that of the three Sage Kings in antiquity, the last one, $\mathrm{Yu}$, appeared the earliest in these records, during the Western Zhou dynasty, while the other two appeared later, toward the end of the Spring and Autumn period (the first half of the Eastern Zhou dynasty). Based on this discovery, Gu reached two conclusions: first, the myths and legends (such as those of the Sage Kings) in these records should be discerned and distinguished from history - in other words, there should be a demarcation between mythology and history; and second, these myths and legends were mostly fabrications of the later transmitters and recorders, rather than passed down from antiquity $(\mathrm{Gu}$ et al. 1981 [1926]: 59-66).

Of course, Gu's radical position, especially the second conclusion, is not without weaknesses, and was consequently criticized by other scholars. For example, Mark Edward Lewis keenly pointed out that Gu's argument "hinged on the exclusion of less canonical works from the later period" (Lewis 2009: 545), especially The Classic of Mountains and Seas, which is generally regarded as having preserved many myths from antiquity; and his rigid methodology and radical approach have been rejected by many scholars both in and outside China (Su 2012: 123; Birrell 1993: 13). 
In spite of Gu's weaknesses, his research is still of great value today in that it keeps reminding us of the potential risks and traps in the study of Chinese mythology. For the present study, it helps to highlight the difficulty in organizing the myths and legends into chronological order. Difficult it is indeed, but not altogether impossible. The 'tampering and distortions' mentioned above, though inevitable, do not necessarily have to be an obstacle in the study of mythology - Lévi-Strauss once defined a myth as "consisting of all its versions", all of which contain the same underlying structure (1955: 435). Actually, despite the discrepancies between different versions of the same myth/ legend, the core remains the same in most cases, and the recurring motifs stay more or less stable, forming a solid ground for researches. Furthermore, it would perhaps be more proper to regard the 'tampering and distortions' as the development and transformations of the individual myths and legends, which reflect the changing historical circumstances and the tension between different sides in the power struggle. As for the fabrications, they can be detected through a number of devices, such as meticulous textual analysis, inter-textual referencing, and comparison with living tales from the different ethnic groups. Chinese scholarship in recent decades has witnessed great accomplishments in establishing a chronology of Chinese myths and legends - most notably by Yuan Ke in A History of Chinese Mythology (1988b) and Tian Zhaoyuan in Mythology and Chinese Society (1998). In this study I am roughly following their chronologization.

Based on such a chronology, the transformations of the criticisms in Chinese myths and legends can be divided into four stages, each (cor)responding to the historical circumstances and with its own distinct feature, as is shown below. But it should be noted beforehand that the divisions between the four stages are not clear-cut, but rather there should necessarily be overlaps between the stages, as the transitions from one stage to another occurred only gradually, and sometimes tales of an earlier stage persisted long after the new stage had set in. But despite the overlaps, the general outline of the four stages is clear.

The first stage is, strictly speaking, a stage with no criticism in Chinese myths and legends. Manifest social and political criticism would only arise when there are large-scale inequalities, exploitation and injustice, which were almost non-existent at the time. Because of the low productivity, everyone had to work and share the output more or less equally, and the most important task was to get food out of nature rather than out of others' mouths. Moreover, as nature did not always provide enough food and oftentimes became harsh and inclement, how to cope with it became a primary concern, and that concern found its way into myths and legends. In other words, myths and legends from this stage deal primarily with the relationship between man and nature, 
rather than that between man and man. In these myths and legends, nature is often presented as an unfriendly and sometimes even hostile force. In general, there is a wish to overcome this force so as to make life easier, and sometimes a direct confrontation between man and nature can be detected. As Marx once put it, "All mythology masters and dominates and shapes the forces of nature in and through the imagination" (1986: 19). Even though his statement is a bit too assertive, it undoubtedly fits the majority of myths and legends from this stage. Tales such as "Nüwa patching up the sky" and "Great Yu controlling the flood" reflect the hardships the masses went through during natural disasters, and the consequent wish to be delivered by Gods or heroes; "Kuafu chasing the sun" and "The foolish old man removing the mountains" show the courage to emulate nature; and "Jingwei filling up the sea" even demonstrates antagonism against a hostile nature - the youngest princess of the Yan emperor, having been drowned by a hurricane, swore vengeance on the sea, and turned into the bird Jingwei, which incessantly carried pebbles and twigs and threw them into the sea, trying to fill it up. In these myths and legends, the tension is between man and nature rather than between man and man: few political authorities or human power struggles are detected. What is more, nature in these stories is not personified, but presented as nature itself. Thus it can be seen that myths and legends from the first stage were largely non-critical.

The transition from the first to the second stage occurred very slowly, since the productivity in the primitive society developed only in a piecemeal fashion. Nevertheless, the slow transition got reflected in myths and legends. I regard the tale "Yi shooting down nine suns" as marking that transition. According to the tale, at the time there were ten suns that shone simultaneously in the sky, which caused a great drought upon earth. In order to deliver the masses from the disaster, Yi the great archer shot down nine suns, leaving only one to perform its duty in the sky. From such a reading this tale is not different from the other tales about delivery from natural disasters. However, the interesting thing is that the ten suns were not just natural suns, but personified as the sons of Di Jun, God of the Eastern Heaven. What is more interesting is that Yi was actually a minor god sent by Di Jun to teach his mischievous sons a lesson but not to hurt them. Di Jun even provided Yi with the bow and arrows. However, when Yi arrived upon earth, the miserable scene infuriated him so much that he shot down the suns one by one; he had the intention to kill them all, and was only stopped because his last arrow was stolen by someone sent by the king on earth. And he was later banished from heaven because of his disobedience (Yuan 1988a: 289-298). I regard this tale as marking the transition from the first to the second stage because in it, the hostile force of nature is identified 
with repression from 'above', and Yi's disobedience shows a challenge of the authorities for the benefit of the masses.

The second stage witnessed the emergence and flourishing of criticisms in myths and legends, and a distinctive feature of this stage is that criticisms usually took the form of direct confrontation with the authorities. Criticisms appeared, on the one hand, because thanks to the advancement of technology and productivity, the masses were better safeguarded against the hostile forces of nature; and on the other hand, because inequalities, exploitation, and injustice emerged and intensified, which resulted in the antagonism between the masses and the authorities. These changes shifted the attention from the relationship between man and nature to that between man and man, the latter of which became a major concern in myths and legends. Another salient feature of these critical tales is the persistent revenge motif in them. The revenge is carried out, almost invariably, because an injustice has been done earlier by the authorities. Taken together, the confrontational manner and the revenge motif reflect, on the one hand, the appearance of large-scale inequalities, exploitation, and injustice; and on the other, the absence, or underdevelopment, of censorship, which gave the tale-tellers a free rein in venting their dissatisfaction and anger.

The earliest tale of this type is perhaps that of Xing Tian, who was originally a minister of the Yan Emperor. After the latter's defeat by the Yellow Emperor and the failure of the revolt by another former follower of the Yan Emperor, the infuriated Xing Tian went to challenge the Yellow Emperor himself. A fierce duel ensued, in which Xing Tian was decapitated and his head buried in Changyang Mountain. However, this is not the end of the story, for the headless Xing Tian did not surrender or die immediately, but, using his nipples as eyes and his navel as mouth, continued to fight with his axe and shield (Yuan 1988a: 151-152). Such an indomitable fighting spirit is typical of tales from the second stage. Xing Tian failed in the end, but in the later stories of this type, the revenge after the hero's own death often succeeded. For example, after having been killed by king Kong Jia of Xia, the ghost of Shi Men the dragon tamer caused a fire in the woods and frightened the superstitious king to death; and after being wrongly executed by King Xuan of Zhou, the ghost of Dubo avenged himself by shooting the king while the latter was hunting (Yuan 1988a: 291, 341). Stories of this type persisted until the Warring States period, when the motif of revenge was developed into highly elaborated plots, as is best represented by the story of Chi, the son of the great swordsmiths Gan Jiang and Mo Ye, which was later recorded in In Search of the Supernatural. After forging two swords, one male and one female, for the king of Chu, Chi's father knew that he was going to be killed by the king. So he buried the male sword and presented only the female 
one to the king, who killed him in a fit of wrath. Chi grew up, learned about the story, and decided to avenge his father. He dug out the male sword and set out. On his way he met a wanderer who promised to help him. Chi was glad and cut off his own head and gave it, together with the sword, to the wanderer. The latter then went to the palace and presented the head and the sword to the king, who was exhilarated, because he had formerly dreamed that he was killed by the young man, and consequently offered a thousand in gold for the young man's head. The wanderer advised the king to boil the head in a great cauldron, and the king did it. But the strange thing is that "even after three whole days and three nights the head did not break down, but rather leaped up in the boiling water to glare angrily at the King" (Gan 1996: 125). The wanderer then suggested a close inspection by the king for the head to "cook away", and when the latter drew near, he "unsheathed the male sword and struck the King's head off and into the boiling water. He then cut off his own head, and it too fell into the cauldron. All the heads then dissolved, so they could not be distinguished from one another". The three indistinguishable heads were finally buried together in the "Tomb of Three Kings" (Gan 1996: 125-126). What is noticeable in this story, besides the continuing revenge motif, is the ending when the three heads become indistinguishable, which possibly reflects a yearning to return to the classless society, when the kings were not yet distinguished from the masses and little exploitation or oppression existed.

Stories of the second type continued all the way till the Warring States period, but came to an almost abrupt halt in the Qin dynasty. This is probably because before the Qin dynasty, the political and cultural environment was comparatively loose, and the masses enjoyed more freedom of speech. However, after establishing the first unified empire in Chinese history, Emperor Qin Shi Huang carried out a series of policies to strengthen both the administrative and the ideological control over the empire, which resulted in what some scholars regarded as "one of the earliest totalitarian superpowers in world history" (Kulmar 2014: 165). The severest measure taken to achieve the latter purpose was the notorious burning of books and burying the scholars (焚书坑儒), which was unprecedented in Chinese history. As a result, ideological control tightened and tales about direct confrontation with authorities could no longer be tolerated. This forced the criticism in myths and legends to take a different form, and brought it to the third stage. Criticisms at this stage were more indirect, usually launched through tales about the unfair treatment and hardships the protagonists go through within the unjust and oppressive system; more often than not the protagonists are a pair of lovers torn apart by the repressive apparatuses and/or ideological dogmas. As Emperor Qin Shi Huang played a pivotal role in bringing about this transformation, there is a story of this type which 
is directly related to him - that of Lady Meng Jiang. According to the story, Meng's husband was conscripted by the Emperor to build the Great Wall, and died because of the hard labor. Meng, having heard nothing from her husband, set out to visit him on the construction site, only to find him dead when she arrived. Grief-stricken, she could not help wailing, and her wailing was so bitter that a part of the Great Wall collapsed, revealing the bones of her husband. The story is obviously critical of the repressive system, but it does so by telling a tragic story in order to arouse the readers' sympathy for the couple and hatred for the oppressors, rather than in a direct confrontational manner, as tales from the second stage did. What is more interesting than the story itself is the transformations it went through. As has been said before, the development and transformations of the individual myths and legends could reflect the changing historical circumstances and the tension between different sides in the power struggle, and this story is a very good case. Actually the embryonic form of the story had already existed before the Qin dynasty, yet at the time it was set in the Dukedom of Qi, and did not contain the wall-crumbling episode, which means that it was totally unrelated to Qin Shi Huang. However, during the transmission, the setting was transplanted and the new episode added, making Qin Shi Huang responsible for the tragedy (Idema 2008: 5-7). The development and transformations of this story show how the structure of feeling of the storytellers changed in accordance with the changing historical circumstances, and how the first emperor in Chinese history was remembered as a cruel and repressive figure.

The story of Lady Meng Jiang is one of China's four great folktales, the other three being "Butterfly lovers", "Xu Xian and his white-snake wife", and "Cowherd and weaving girl". What is interesting to note is that all of these tales are from the third stage and share the 'torn-apart-lovers' motif, although the force which tears the lovers apart varies from one tale to another. Of these stories, the one about the white-snake wife is undoubtedly the most interesting, as it also went through a series of transformations that changed its critical thrust. In the earliest record of this story by Feng Menglong in Stories to Caution the World, Lady Bai, the white-snake wife, is depicted as a seductive but demonic figure, which is quite different from the image with which most Chinese are familiar today. She stole silver from others' vault and clothes from a pawnshop, and cruelly threatened Xu Xian (her husband) that if he should betray her, she would "drench the whole town [Hangzhou] in a bloodbath and toss everyone from wave to wave in the river until all die violent deaths" (Feng 2005: 500). And in this version it is Xu Xian who placed the magic bowl over Lady Bai's head to capture her, because he wanted to get out of her control. Moreover, at the end of the story it is Xu Xian, not Fahai the monk, who collected donations 
and built the Thunder Peak Pagoda in order to trap Lady Bai underneath forever. At this stage the story was just a demon tale and Lady Bai's image a femme fatale. However, such an image was gradually transformed into a loving and devoting wife: the thefts turned into Lady Bai stealing the immortal herb from the Southern Pole Palace in order to save her husband, who was on the brink of death; and the threat to drench Hangzhou became the flooding of Golden Mountain Monastery (水漫金山寺), which was done in order to save her husband, who was trapped inside. At this stage the story put on a smack of confrontation, as Lady Bai became a daring figure who defied and challenged dogmatic rules and ideological boundaries for her loved one. This is especially prominent in the flooding episode, for Lady Bai "mobilized all creatures of rivers and seas, and Fahai responded by calling on all the protective deities of Buddhism for help" (Idema 2009: xvii), which reads like a rebellion from 'below' against the 'above'. In this sense, it is somehow even reminiscent of the tales from the second stage, although in the end it is the 'torn-apart-lovers' motif that triumphed, for Lady Bai was trapped beneath the pagoda by Fahai the monk, who represents the ideological authorities. However, this was not the end of the transformations, for after the story was performed on stage, the audience's longing for a happy ending induced the actors to make further adaptations, adding the role of a son born to Lady Bai and Xu Xian, who grew up to participate in the Imperial Examination (科举), won the top position, and finally liberated her mother from the pagoda (Idema 2009: xvii-xviii). It is noteworthy that the son's measure to liberate his mother is through participation in the state apparatus and serving the authorities (or becoming one of them), rather than defying and challenging them as his mother did. In this way the critical spirit of the story is much reduced.

The story of the white-snake wife allegedly took place in the Southern Song dynasty, but the recording and adaptations of it were done largely during the Ming dynasty, which made it overlap with the fourth stage. In this stage, criticisms in myths and legends were usually expressed in the form of satires. This is probably due to the literary inquisition - the persecution of intellectuals because of the allegedly instigative or rebellious passages in their writings, which were in most cases 'detected' only through far-fetched and distorted interpretations. Historically literary inquisitions had occurred occasionally throughout centuries, but it intensified at the beginning of the Ming dynasty. Zhu Yuanzhang, the founder of the Ming dynasty, attributed the downfall of the previous empire to its leniency, and his "abhorrence of free speech" prompted him to carry out a series of literary inquisitions (Luo 2011: 655). As a result, the Ming dynasty, "from the very beginning of its establishment, tried to cast the personality of 
men of letters in a slavish mould" (Luo 2011: 656). The situation deteriorated during the Qing dynasty, which was notorious for this practice, especially during the reign of emperor Qianlong (Mote 2003: 926-928). Such a tight control of speech forced criticisms to take even more subtle and surreptitious forms, and satirical tales, dressed up in harmless fantastic outfits, appeared to be a prime choice.

Two satirical works, one from each of these two dynasties, deserve special attention.

The Ming dynasty witnessed the appearance of Journey to the West, a highly satirical work in the form of a fantastic novel. Its protagonist, the Monkey King, is a figure that is familiar to almost every Chinese, and perhaps the most daring and rebellious character in Chinese literature. Although in terms of structure, the novel develops along the taming and domestication of the Monkey King, and his final achievement of Buddhahood, which symbolizes his incorporation into the ideological system, the subtext of the novel reads otherwise, for the Monkey King's submission is in many ways only apparent, and his aversion to oppression and ideological control persists to the very end. This is best demonstrated in the last chapter of the novel: immediately after achieving Buddhahood, the Monkey King asks his master to loosen the golden band (紧箍咒) - a symbol of ideological control - on his head:

'Master,' Monkey said to the Tang Priest, 'now that I've become a Buddha just like you, surely I don't have to go on wearing this golden band. Do you plan to say any more Band-tightening Spells to tighten it round my head? Say a Band-loosening Spell as quickly as you can, take it off, and smash it to smithereens. Don't let that Bodhisattva or whatever she is make life miserable for anyone else with it.' (Wu 2005: 1042; emphasis added)

The grudge against the Bodhisattva (authorities) and the hatred for the golden band (ideological control) is obvious here. Actually throughout the book Wu never stops mocking and deriding different forms of authorities: secular, divine, infernal, Taoist, Buddhist, Confucian.... Such mocking and derision finally result in the disruption and dissolution of authorities, which form the core of the novel's critical thrust:

Authority is vested in personages (mortal and immortal), laws (worldly and heavenly), things (weapons, magic treasures), and ideas and texts, particularly the Heart Sutra and the Buddhist scriptures. [But these] various kinds of authority are displayed and challenged, and ... in the ultimate conclusion of the journey, authority is completely dissolved. (Adams 2006: 117) 
In the Qing dynasty, the best satirical work in fantastic literature is undoubtedly Strange Stories from a Chinese Studio by $\mathrm{Pu}$ Songling, a collection of 491 supernatural tales, mostly related to ghosts, demons, foxes, and other spirits. Of these tales, there are many that are highly critical of his time. $\mathrm{Pu}$, an intellectual who had repeatedly participated and failed in the Imperial Examination, unlike the actors who adapted the story of the white-snake wife, cherished no unrealistic fantasies about the examination system, seeing it as nothing but a way the rulers used to control and enslave the intellectuals and select bureaucrats with no independent spirit. Therefore, there are quite a few pieces in the book which expose and satirize the examination system, showing how intellectuals who are upright and capable are almost without exception excluded from the state apparatus, while sycophants and hypocrites are selected. Besides, there are also pieces that reveal and mock the corruption and cruelty of the rulers in very subtle ways. For example, in a story called "Three Lives", a bureaucrat who has "often behaved immorally" during his lifetime is after his death reincarnated in the forms of a horse, a dog, and a snake in three consecutive lives, and suffers great pains as animals ( $\mathrm{Pu}$ 1979: 29-30). The whole story reads like a banal Buddhist tale of reincarnation, but for the comment the author attaches at the end: "Within the beasts are the spirits of kings and dukes and great ones; this is so because in the kings and dukes and great ones, there are also spirits of beasts" ( $\mathrm{Pu}$ 1979: 30). The most satirical piece in the work is perhaps "The cricket", which tells how the protagonist's comatose son became a cricket and was sent to the palace to please the emperor, who loved cricket-fighting. Although the story has a happy ending, with the protagonist rewarded and becoming rich, and the son recovering from coma, one gets a sense of black humor because the subtext of the story symbolically reminds one that the masses, like the crickets, are but playthings of the emperor and subject to his whims, just as the author puts in the comment: "A single step of the emperor may trample many people to death" (Pu 1979: 208).

Thus it can be seen that criticisms of the fourth stage largely abandoned the 'torn-apart-lovers' motif of the third stage, because even that may seem a bit obvious and, consequently, unacceptable. The adaptations of the white-snake wife story by the actors mentioned above may reveal, besides a wish to please the audience, also an act of self-censorship when confronted with the strategy of the state apparatus. Self-censorship, however, is not the only way to cope with the intensified strategy in ideological control; another way is to develop even more subtle and ingenious tactics to deliver the message in a more surreptitious way. And that is precisely what criticisms of the fourth stage did when resorting to satires. 


\section{CONCLUSION}

From the survey in the previous section it is clear that Chinese myths and legends are indeed a field of power struggle in which different forces play out. As historical circumstances changed, these forces also resorted to different strategies and tactics in their play, which resulted in the transformations of the criticisms in these myths and legends, just as Malinowski (1948: 122) once observed: "every historical change creates its mythology". Thus, Chinese myths and legends were not an isolated field; their development was closely associated with the development of Chinese history. The historicity of Chinese myths and legends is what this study ultimately rests upon, and that historicity is most saliently manifested in the embedded social and political criticisms.

Of course, this study is not without its limits. Because of the broad scope, it could only conduct a general survey, without going deeper in analyzing the individual myths and legends. Besides that, there are also a number of ways in which further researches may be carried out to deepen our understanding of this field.

Firstly, in studying the power struggles within the field of Chinese myths and legends, I focused on the struggle between the ruling classes and the masses. However, this should not be taken as exclusive, because there were certainly other struggles as well - for example, between different ethnic groups, different genders, or even different ruling cliques - which could be the subject matter of further studies.

Secondly, in studying the embedded criticisms, my approach was mainly 'responsive', i.e., focusing on how the criticisms responded to changing historical circumstances in their transformations. Another approach to this subject would be 'reactive', namely, analyzing the influence of these myths and legends on society in order to see how they helped to facilitate or even direct social transformations. For example, toward the end of the dynasties, leaders of revolutions would usually use myths and legends to rally the masses. This would also be a direction worth exploring.

Last but not least, as has been said before, the embedded criticisms ultimately derived from the dissatisfaction and anger of the masses. But these criticisms were not the only product of the dissatisfaction and anger; another important product is the creation of utopias, which also found their way into Chinese myths and legends. From the country which Great Yu allegedly visited, where the people, freed from hunger and labor because a magical fountain provided all the nutrition they needed, played music all day long (Yuan 1988a: 276); to the 'happy land' in The Book of Songs; to the Peach Blossom Land (桃花源) 
separated from the secular world and freed of its exploitations and corruption; to the Land of Decent Men (君子国) in Flowers in the Mirror, such a longing never stopped. Further studies may also be conducted with regard to this topic.

\section{NOTES}

${ }^{1}$ Chu was a kingdom during the Eastern Zhou Dynasty, when the authority of the Zhou emperor was on the decline and several powers vied with one another for supremacy. But unlike most of the other powers, which were located in the northern part of China, along the Yellow River, the kingdom of Chu was located in the south, along the Yangtze River. Culturally it was also distinct from the others in its Taoist tradition (as opposed to the Confucian tradition from the north) and its rich myths and legends, which were largely preserved in The Songs of Chu.

\section{REFERENCES}

Adams, Roberta E. 2006. Aspects of Authority in Wu Cheng'en's Journey to the West. In: Peter D. Hershock \& Roger T. Ames (eds.) Confucian Cultures of Authority. Albany: State University of New York Press, pp. 117-150.

Allan, Sarah 1981. The Heir and the Sage: Dynastic Legend in Early China. Taipei: Chinese Materials Center.

Birrell, Anne 1993. Chinese Mythology: An Introduction. Baltimore: The Johns Hopkins University Press.

Bourdieu, Pierre 1993. The Field of Cultural Production: Essays on Art and Literature. Edited by Randal Johnson. New York: Columbia University Press.

Confucius 2003. Analects: With Selections from Traditional Commentaries. Transl. by Edward Slingerland. Indianapolis \& Cambridge: Hackett Publishing Company.

Feng, Menglong (ed.) 2005. Stories to Caution the World: A Ming Dynasty Collection. Vol. 2. Transl. by Yang Shuhui \& Yang Yunqin. Seattle: University of Washington Press.

Feng, Youlan 1952. A History of Chinese Philosophy. Vol. 1. Transl. by Derk Bodde. Princeton: Princeton University Press.

Gan, Bao 1996. In Search of the Supernatural: The Written Record. Transl. by Kenneth J. DeWoskin \& James Irving Crump. Stanford: Stanford University Press.

Ge, Zhaoguang 1987. Xiang xiang de shi jie: Dao jiao yu zhong guo gu dian wen xue. [The World of Imagination: Taoist Religion and Classical Chinese Literature.] Wen xue yi chan [Literary Heritage], No. 4, pp. 21-30.

Gu, Xiegang (ed.) 1981 [1926]. Gu shi bian. [Critiques of Ancient History.] Vol. 1. Shanghai: Shanghai Classics Publishing House.

Hu, Shi 1999 [1928]. Bai hua wen xue shi. [A History of Literature in Vernacular Chinese.] Shanghai: Shanghai Classics Publishing House. 
Idema, Wilt L. 2008. Meng Jiangnü: The Development of a Legend. In: Wilt L. Idema (transl.) Meng Jiangnü Brings Down the Great Wall: Ten Versions of a Chinese Legend. Seattle \& London: University of Washington Press, pp. 3-23.

Idema, Wilt L. (ed. \& transl.) 2009. The White Snake and Her Son: A Translation of the Precious Scroll of Thunder Peak with Related Texts. Indianapolis: Hackett Publishing Company.

Kulmar, Tarmo 2014. On the Nature of the Governing System of the Qin Empire in Ancient China. Folklore: Electronic Journal of Folklore, Vol. 59, pp. 165-178. http://dx.doi.org/10.7592/FEJF2014.59.kulmar.

Lévi-Strauss, Claude 1955. The Structural Study of Myth. The Journal of American Folklore, Vol. 68, No. 270, pp. 428-444. http://dx.doi.org/10.2307/536768.

Lewis, Mark Edward 2009. The Mythology of Early China. In: John Lagerwey \& Marc Kalinowski (eds.) Early Chinese Religion. Part One: Shang through Han (1250 BC-220 AD). Leiden: Brill, pp. 543-594. https://doi.org/10.1163/ ej.9789004168350.i-1312.86.

Luo, Yuming 2011. A Concise History of Chinese Literature. Transl. by Ye Yang. Leiden: Brill. https://doi.org/10.1163/9789004203679.

Malinowski, Bronislaw 1948. Magic, Science and Religion and Other Essays. Boston, Mass.: Beacon Press. Available at https://monoskop.org/images/4/41/Malinowski_ Bronislaw_Magic_Science_and_Religion_and_Other_Essays_1948.pdf, last accessed on 21 March 2019.

Mao, Dun 2011 [1928]. Zhong guo shen hua yan jiu chu tan. [A Preliminary Study of Chinese Mythology.] Shanghai: Shanghai Classics Publishing House.

Marx, Karl 1986. Karl Marx: A Reader. Edited by Jon Elster. Cambridge: Cambridge University Press.

McNeal, Robin 2012. Constructing Myth in Modern China. The Journal of Asian Studies, Vol. 71, No. 3, pp. 679-704. http://dx.doi.org/10.1017/S0021911812000630.

Mote, Frederick W. 2003. Imperial China 900-1800. Cambridge, MA: Harvard University Press.

$\mathrm{Pu}$, Songling 1979. Liao zhai zhi yi. [Strange Stories from a Chinese Studio.] Vol. 1. Shanghai: Shanghai Classics Publishing House.

Segal, Robert A. 2004. Myth: A Very Short Introduction. Oxford \& New York: Oxford University Press.

$\mathrm{Su}$, Yongqian 2012. Shi jie yan guang yu zhong guo xue wen: Ye Shuxian shen hua xue si xiang lun lüe. [Global Vision and Chinese Learning: On Ye Shuxian's Thought of Mythology.] Xin jiang da xue xue bao [Journal of Xinjiang University (Philosophy, Humanities \& Social Science)], Vol. 40, No. 3, pp. 119-124.

Tang Poems 2011 [2004] = Wang's Translation of 300 Tang Poems 2011. Transl. by Wang Yushu. Beijing: China Intercontinental Press.

The Book of Songs 2005 [1937]. Transl. by Arthur Waley. Abingdon \& New York: Routledge.

Tian, Zhaoyuan 1998. Shen hua yu zhong guo she hui. [Mythology and Chinese Society.] Shanghai: Shanghai People's Press.

Williams, Raymond 1965 [1961]. The Long Revolution. Harmondsworth: Penguin Books. 
Wu, Bing'an 2009. Zhong guo shen hua bai nian fan si (xia). [A Reflection on the Study of Chinese Mythology in the Past One Hundred Years (Part Two).] Min jian wen hua lun tan [Forum of Folk Culture], Vol. 195, No. 2, pp. 5-15.

Wu, Cheng-en 2005. Journey to the West. Transl. by W. J. F. Jenner. Blackmask Online. Available at http://www.lxwc.com.cn/ebook-1237546-1.html, last accessed on 25 March 2019.

Yang, Lihui, \& An, Deming 2005. Handbook of Chinese Mythology. Santa Barbara: ABC-CLIO.

Ye, Shuxian 2010. Shen hua zuo wei zhong guo wen hua de yuan xing bian ma: Zou chu wen xue ben wei de shen hua guan. [Mythology as the Archetypal Code of Chinese Culture: Out of the Literature-Oriented View on Mythology.] Zhong guo she hui ke xue bao [Chinese Social Sciences Today] [Beijing] 12 August.

Yuan, Ke 1988a. Zhong guo shen hua chuan shuo: Cong Pan Gu dao Qin Shi Huang. [Chinese Myths and Legends: From Pan Gu to Qin Shi Huang.] Vol. 1. Beijing: People's Literature Publishing House.

Yuan, Ke 1988b. Zhong guo shen hua shi. [A History of Chinese Mythology.] Shanghai: Shanghai Literature and Art Press. 